\title{
Assessment of Alaska Rain-on-Snow Events Using Dynamical Downscaling
}

\author{
Peter A. BienieK, ${ }^{\mathrm{a}}$ Uma S. Bhatt,${ }^{\mathrm{b}, \mathrm{c}}$ JOHn E. WAlsh,${ }^{\mathrm{a}}$ Rick LAder,${ }^{\mathrm{a}, \mathrm{b}}$ Brad Griffith, ${ }^{\mathrm{d}}$ \\ JENNIFER K. ROACH, ${ }^{\mathrm{e}}$ AND RICHARD L. THOMAN ${ }^{\mathrm{f}}$ \\ a International Arctic Research Center, University of Alaska Fairbanks, Fairbanks, Alaska \\ ${ }^{\mathrm{b}}$ Department of Atmospheric Sciences, University of Alaska Fairbanks, Fairbanks, Alaska \\ ${ }^{\mathrm{c}}$ Geophysical Institute, University of Alaska Fairbanks, Fairbanks, Alaska \\ ${ }^{\mathrm{d}}$ U.S. Geological Survey Alaska Cooperative Fish and Wildlife Research Unit, University of Alaska Fairbanks, Fairbanks, Alaska \\ ${ }^{\mathrm{e}}$ Institute of Arctic Biology, University of Alaska Fairbanks, Fairbanks, Alaska \\ ${ }^{\mathrm{f}}$ NOAA/National Weather Service Alaska Region Headquarters, Anchorage, Alaska
}

(Manuscript received 2 October 2017, in final form 24 May 2018)

\begin{abstract}
The ice formed by cold-season rainfall or rain on snow (ROS) has striking impacts on the economy and ecology of Alaska. An understanding of the atmospheric drivers of ROS events is required to better predict them and plan for environmental change. The spatially/temporally sparse network of stations in Alaska makes studying such events challenging, and gridded reanalysis or remote sensing products are necessary to fill the gaps. Recently developed dynamically downscaled climate data provide a new suite of high-resolution variables for investigating historical and projected ROS events across all of Alaska from 1979 to 2100. The dynamically downscaled reanalysis data of ERA-Interim replicated the seasonal patterns of ROS events but tended to produce more rain events than in station observations. However, dynamical downscaling reduced the bias toward more rain events in the coarse reanalysis. ROS occurred most frequently over southwestern and southern coastal regions. Extreme events with the heaviest rainfall generally coincided with anomalous high pressure centered to the south/southeast of the locations receiving the event and warm-air advection from the resulting southwesterly wind flow. ROS events were projected to increase in frequency overall and for extremes across most of the region but were expected to decline over southwestern/southern Alaska. Increases in frequency were projected as a result of more frequent winter rainfall, but the number of ROS events may ultimately decline in some areas as a result of temperatures rising above the freezing threshold. These projected changes in ROS can significantly affect wildlife, vegetation, and human activities across the Alaska landscape.
\end{abstract}

\section{Introduction}

During the winter months much of the Alaska and Arctic landscape is frozen and covered with snow. When rain falls on snow or frozen surfaces it freezes and ice accumulates. The ice accumulated from these rain-onsnow (ROS) events poses dangers to transportation and wildlife. Unlike lower latitudes, sustained below freezing temperatures are common throughout much of Alaska in winter (Shulski and Wendler 2007) and icing on roads from rainfall can have sustained impacts with treacherous driving conditions lasting until the spring melt. Water from ROS events freezes into ice layers on the ground or in the snowpack and can lead to increased stress on Arctic wildlife by limiting access to their food underneath

Corresponding author: Peter A. Bieniek, pbieniek@alaska.edu
(Hansen et al. 2011; Rennert et al. 2009). Such events have consequently been a concern of subsistence users in areas of Alaska because they can lead to mortality or redistribution of wildlife and reduced access to resources (Kruse et al. 1998). The ice from these events can also impact permafrost and vegetation by altering the heat budget of the snowpack (Putkonen and Roe 2003). The climate of Alaska is currently warming relatively rapidly under Arctic amplification (Serreze and Barry 2011) and is projected to continue to warm over the next century (IPCC 2013). As a consequence of the warming climate, ROS events are generally expected to increase in frequency across the Arctic (Putkonen and Roe 2003; Rennert et al. 2009). Understanding the spatial distribution, climatic behavior, variability, and atmospheric circulation drivers of ROS events is therefore important to better predict these impactful events and to better plan 
for their future effects on the economy and the terrestrial ecosystems of Alaska.

Most ROS events occur from November to March in southern coastal regions of Alaska (Cohen et al. 2015; Jeong and Sushama 2018; Liston and Hiemstra 2011; Putkonen and Roe 2003; Rennert et al. 2009; Wilson et al. 2013). These regions have warmer and wetter climates in winter than the continental colder/drier interior and northern climate divisions (Bieniek et al. 2012) and, therefore, are more likely to see rain or mixed precipitation during the cold season (McAfee et al. 2014). Limited analysis of the atmospheric circulation drivers of Alaska ROS events has been conducted for western Alaska, showing enhanced southerly warm-air advection as a key driver (Rennert et al. 2009).

The temporally and spatially sparse network of weather stations in Alaska poses a major challenge for studying ROS events and requires the use of gridded reanalysis and/or remote sensing products to help fill the gaps. The use of dynamical downscaled data is particularly advantageous because historical reanalysis and future projections from global climate models (GCMs) can be compared in a consistent framework at a relatively high spatial and temporal scales. This study assesses the climatic behavior, variability, atmospheric circulation drivers, and projected change of ROS events throughout Alaska using a novel dynamically downscaled suite of reanalysis and GCM future projections. These data provide the longest period of high spatial resolution climate data available over the entire Alaska domain and their efficacy in capturing ROS events is evaluated. In addition, this study identifies the atmospheric circulation drivers of historical and projected change in extreme ROS events at six key population centers in Alaska.

\section{Data and methods}

Dynamically downscaled reanalysis and GCM projections of future climate were used to analyze past and future projections of ROS events in Alaska. The downscaling was conducted using the Advanced Research (ARW) version of the Weather Research and Forecasting (WRF) Model (Skamarock et al. 2008) over the entire Alaska domain (see Fig. 1a; Bieniek et al. 2016). The 20-km spatial resolution of these downscaled data accounts for the complex topography of Alaska better than relatively coarse reanalysis or GCM data (Bieniek et al. 2016). The daily temporal resolution of the downscaled data enabled the detection of extreme ROS events that occur on a daily time scale. The WRF Model was reinitialized at 48-h intervals with an additional 6-h spinup time and a spectral nudging procedure that constrained the downscaled fields to be consistent with the driving reanalysis or GCM. Clouds and precipitation in the WRF Model were parameterized by the Morrison two-moment (Morrison et al. 2009) and Grell 3D cumulus schemes. Shortwave and longwave radiative effects were parameterized by the Rapid Radiative Transfer Model for GCMs (Iacono et al. 2008). Boundary layer and surface-layer processes utilized the Mellor-Yamada-Janjić (Janjić 1994) and Janjić Eta (Monin-Obukhov) schemes, respectively. A thermodynamic sea ice model (Zhang and Zhang 2001) was coupled with the Noah land surface model used within WRF to better model the thermal conditions over sea ice. The WRF Model configuration, physics, and procedure used to downscale the data for this study were described and evaluated in Bieniek et al. (2016).

Reanalysis data from ERA-Interim (Dee et al. 2011) were downscaled for the period 1979-2013 to provide the historical observations while the GFDL CM3 and NCAR CCSM4 model RCP8.5 scenario from phase 5 of the Coupled Model Intercomparison Project (CMIP5) were downscaled for 1970-2100. The ERA-Interim was analyzed and downscaled because it was one of the best performing over the Alaska and Arctic domains (Lader et al. 2016; Lindsay et al. 2014). Walsh et al. (2018) show that NCAR CCSM4 and GFDL CM3 ranked first and third, respectively, among 21 CMIP5 GCMs in the simulation of the seasonal cycles of temperature, precipitation, and sea level pressure over Alaska. The RCP8.5 scenario was selected because observed carbon dioxide emissions continue to track that highest forcing scenario (Peters et al. 2013).

Daily rain and snowfall amounts were directly output from WRF and used to identify ROS events. Each grid point was evaluated independently to determine if an ROS event occurred each day. ROS events were identified if daily total rainfall was greater than or equal to $0.254 \mathrm{~mm}$ (equivalent to $0.01 \mathrm{in}$. of precipitation, which is the minimum measurement of the National Weather Service) and any of the following: 1) there was snow on the ground but the daily maximum temperature was lower than $\left.4^{\circ} \mathrm{C}, 2\right)$ the skin temperature was less than or equal to $0^{\circ} \mathrm{C}$, or 3 ) the daily maximum air temperature was less than or equal to $0^{\circ} \mathrm{C}$. This multiple criterion allowed for the identification of rain on frozen ground and rain on snow because both cause significant icing. Hereinafter, we will refer to all events as rain on snow or ROS for simplicity. The additional $4^{\circ} \mathrm{C}$ criterion was added as an upper bound for temperature only for the snow-on-the-ground cases to limit the inclusion of warm ROS in southern coastal areas since these events may not have any impactful ice accumulations because of high temperatures melting the ice/snow. There was 


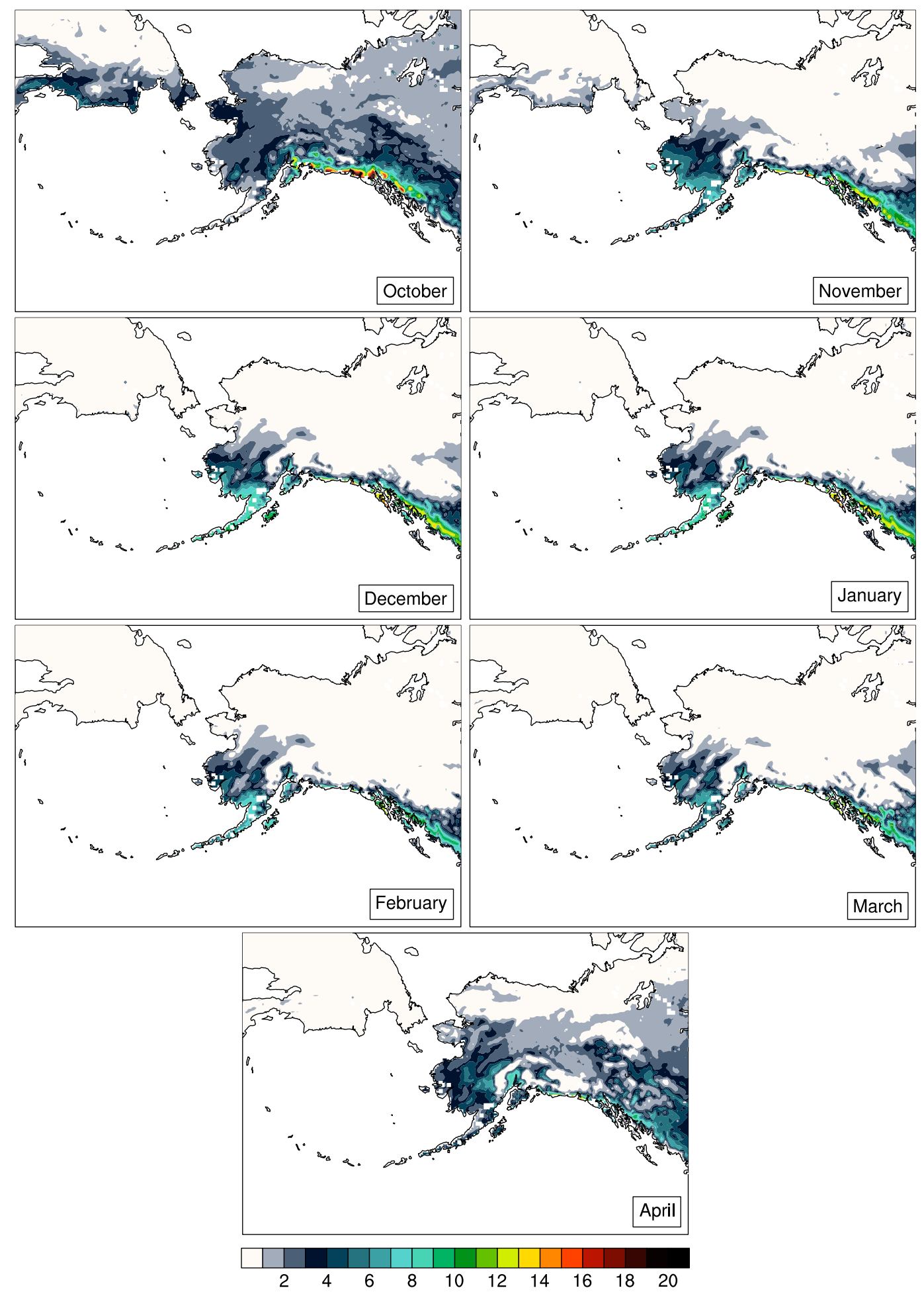

FIG. 1. October-April 1979-2013 monthly climatic averages of the number of ROS days in Alaska derived from the downscaled ERA-Interim. 
intentional redundancy among the other subcriteria, and the $0^{\circ} \mathrm{C}$ skin temperature subcriterion (item 2 above) often captured ROS rain events occurring at air temperatures higher than $4^{\circ} \mathrm{C}$.

The daily ROS identification criterion was applied yearround, but the focal season in this study was winter, which spanned November-March. The same ROS measures were applied to the ERA-Interim, NCAR CCSM4, and GFDL CM3 downscaled data in our analysis. The criterion was also applied to the coarse ERA-Interim data to identify the potential role of the WRF Model physics/ resolution in capturing the magnitude and variability of ROS events. Daily ROS events were then classified and ranked by the total rainfall amount. Days with any rain or mixed rain/snow (with liquid precipitation amounts of $0.254 \mathrm{~mm}$ or greater in both cases) were also identified for all grids and models to help evaluate the ROS results.

The ROS information identified by the downscaled data was evaluated against station and satellite-based observations. Daily meteorological station data for Alaska over 1979-2013 were obtained from the Global Historical Climatology Network Daily (GHCN-D) database maintained by the National Centers for Environmental Information. The database includes numerous, quality controlled historical daily meteorological parameters and integrates multiple data sources (Menne et al. 2012). Because the database does not generally provide a subdivision of rain versus snow precipitation like the WRF output, a direct comparison is not possible. Rainfall, however, is the key variable in ROS and was identified at the stations by the amount of precipitation that fell on days when no snowfall was recorded. This approach has the caveat that snowfall data need to be available for the station for the detection to work properly. In our analysis, we did not include stations or daily records that lacked snowfall information.

Hourly precipitation-type information provided by METAR messages from the network of Automated Surface Observing System stations in Alaska (http:// mesonet.agron.iastate.edu/request/download.phtml) was included to complement the GHCN-D. The 39 stations selected had at least $25 \mathrm{yr}$ of data for 1979-2013 and were a subset of GHCN-D, which included numerous Cooperative Observer Network (COOP) stations that did not report hourly METARs. If any hourly observation included a weather report of rain (i.e., "RA") of any intensity in November-March, that day was identified as a rain day. One caveat with the METAR observations is that weather information could be missing either because of a lack of weather to report or because of a missing observation with no distinction and therefore rain events could be missed. Precipitation amounts also could not be consistently derived from the available hourly Alaska METAR observations and therefore could not be considered. Both station-derived rainfall datasets were compared with the downscaled reanalysis in parallel to provide the fullest evaluation possible since each approach has different strengths and weaknesses.

Satellite detection of rain on snow was more limited in scope than station data but information on icing (a typical product of ROS events) was available from microwave backscatter sensors. Counts of weekly icing events derived from QuikSCAT over 2001-08 for Alaska (Wilson et al. 2013) were utilized in our analysis. The satellite products provide far greater spatial coverage than was available from the stations and is therefore valuable in evaluating against the downscaled data even if only over a relatively short period of record. Because the satellitederived data provided only weekly counts of events and over a shorter period than the downscaled reanalysis and station ROS data, their use was limited to assessing the general climatic spatial patterns of ROS events.

Daily average sea level pressure (SLP) data were obtained from the NCEP-NCAR Reanalysis-1 project (Kalnay et al. 1996) for 1979-2013 on a $2.5^{\circ}$ grid. These global data were used to compute daily composite SLP anomalies for the top 10 ROS days ranked in 1979-2013 by rainfall for eight major population centers in Alaska and were selected to assess circulation patterns that were potentially larger than the scale of the downscaling domain. Our analysis utilized the 1981-2010 climate normal period used by the National Weather Service to compute anomalies. Anomaly significance was determined by a two-tailed $t$ test described by Brooks (1953), and trends were computed by least squares linear regression.

\section{Results and discussion}

\section{a. Variability and validation}

The 1979-2013 climatic averages of the monthly counts of ROS days for October-April derived from the downscaled ERA-Interim are shown in Fig. 1. The ROS events were spatially widespread across most of Alaska in October and April, which are autumn and spring transition months, respectively. In November-March, most events occurred in southwestern and southern coastal areas of Alaska. The region of climatologically most frequent November-March ROS events in southwestern Alaska was situated west of the Alaska Range with a tongue extending inland toward the east on the northern side of the mountains. Southern coastal regions receive eight or more ROS days per month on average while southwestern Alaska receives between one and four days per month in November-March. 

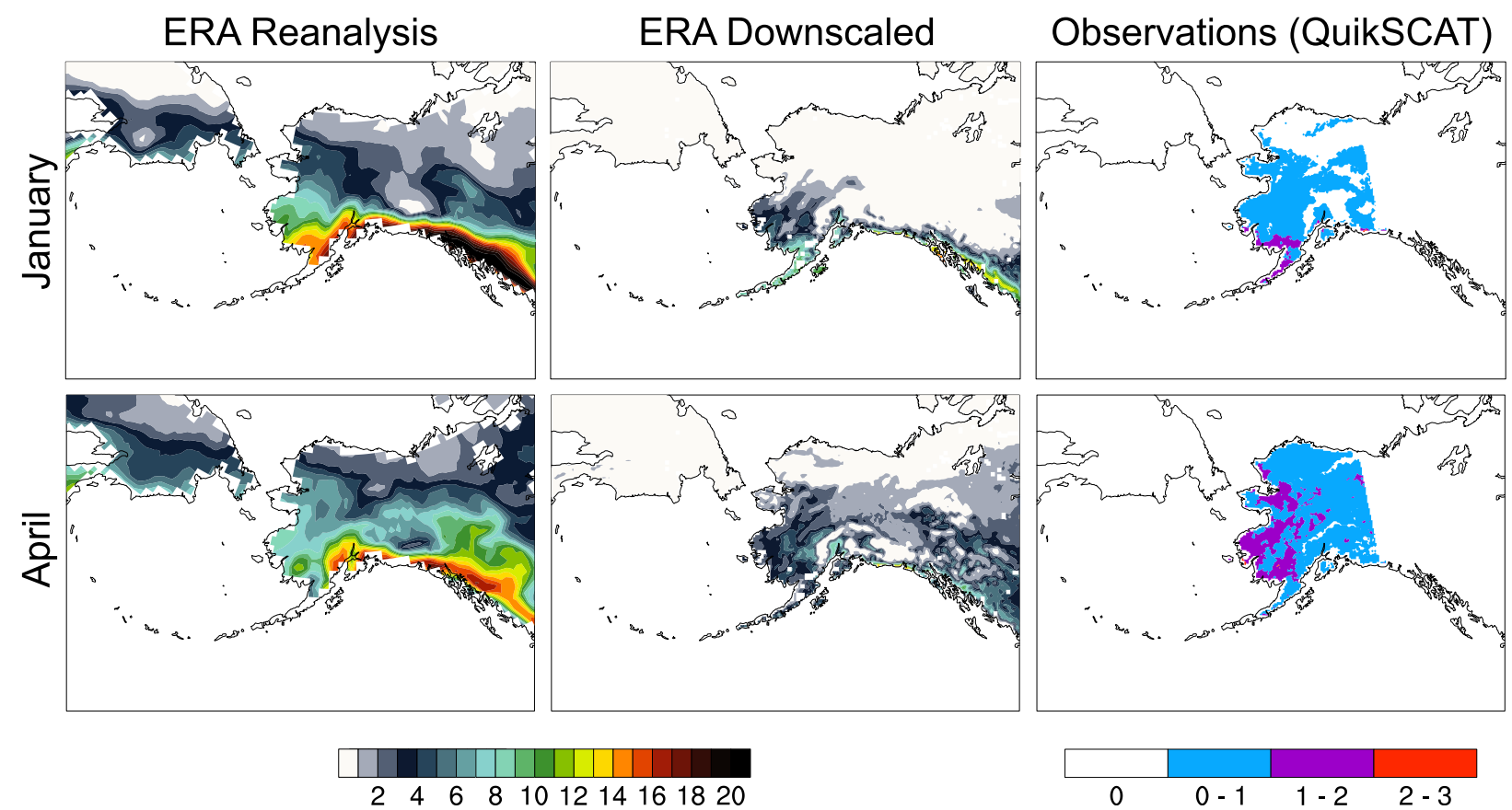

FIG. 2. (top) January and (bottom) April monthly 1979-2013 climatic averages of (left) ERA-Interim and (center) downscaled ERAInterim counts of ROS days along with (right) QuikSCAT-derived 2001-08 monthly averaged counts of thaw-refreeze events (Wilson et al. 2013) in Alaska. Note that the QuikSCAT data only cover mainland Alaska and are counts of events rather than days and therefore do not have the same scale as the ROS-day climatic data.

The spatial patterns of ROS frequency derived from downscaled ERA-Interim were compared with those of satellite icing data for January and April (Fig. 2, center and right). The other months display similar patterns and January (winter month) and April (transition month) are shown for simplicity. The satellite record compares favorably to the ERA-Interim ROS analysis: most January/winter ROS activity was confined to southern and southwestern Alaska coastal regions while the April/transition months display comparable widespread ROS activity. ROS derived from the coarse ERA-Interim (Fig. 2, left) had many more ROS days than the downscaled ERA-Interim or satellite estimates but had similar spatial variability.

Because of the criterion used to identify ROS events, their spatial/temporal variability was linked with that of winter rainfall. The November-March 1979-2013 climatic average of days with rain is shown for the downscaled ERA-Interim and station-derived metrics (Fig. 3). There was broad spatial agreement between the limited observations derived from station METARs, GHCN-D stations, and the downscaled data, but the stations typically had fewer rain days on average than the downscaled data. Most November-March rain days occur in southwestern Alaska and along the southern coasts. Many coastal areas had more than 50 days with rainfall in winter on average while locations in northern and interior Alaska typically had one day or less.

The ability of the downscaled ERA-Interim to capture the timing of rain events through the year was evaluated by comparing it with the METAR-derived rainfall days at the nearest grid points (Fig. 4). The daily GHCN-D rainday comparison with the downscaled data yielded similar results and is therefore not shown. The Heidke skill scores revealed that the downscaled ERA-Interim data best replicated the rain days observed at the stations in southwestern Alaska and southern coastal areas with skill scores of 0.6 and greater (Fig. 4a). The lowest overall skill scores were at interior stations around Fairbanks and at Utqiagvik (Barrow), Alaska. The percentages of rain days observed at the stations and captured by the downscaled ERA-Interim are shown in Fig. 4b. Like the skill scores, the best performance of the downscaled data was along southern and southwestern coastal areas, with nearly $100 \%$ of station rain days accounted for. The areas of interior Alaska in some instances capture $60 \%-80 \%$ of events while more northerly locations only identified $20 \%-40 \%$ of rain days observed at the stations. The overall variability of the November-March numbers of daily rain events was assessed by Pearson's correlation (Fig. 4c). Correlations were positive at all stations, with most being statistically significant at the $95 \%$ or greater 


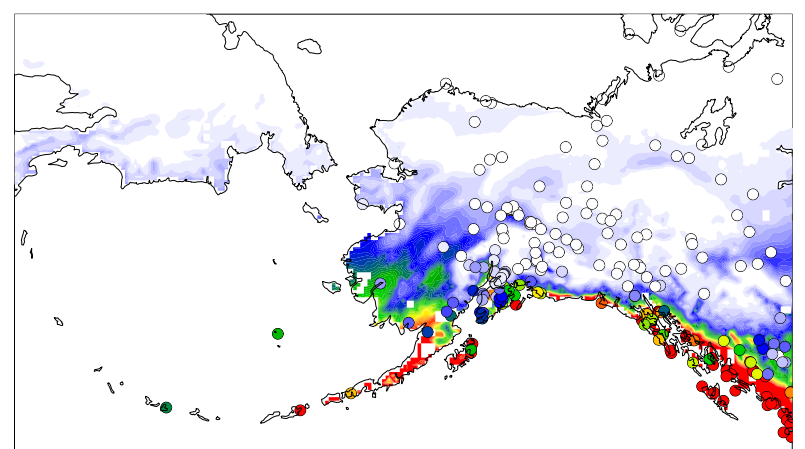

a) GHCN
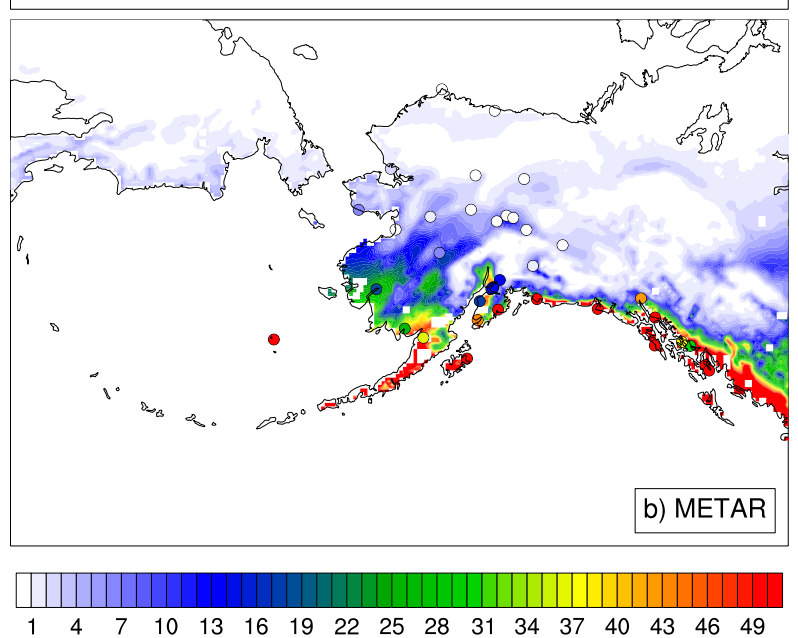

FIG. 3. November-March 1979-2013 average number of days with rainfall in downscaled ERA-Interim [shading in both (a) and (b)] and derived from (a) daily GHCN-D stations precipitation/ snowfall and (b) hourly METAR station weather reports (circles).

level according to a $t$ test, indicating that both station and downscaling had consistent variability in the number of ROS events each year even if the skill of detecting individual event days was relatively low.

For additional validation, station (GHCN-D) and downscaled seasonal rainfall totals during the NovemberMarch winter months were compared by correlation analysis with the station rainfall data (Fig. 5). Roughly $52 \%$ of stations in the full domain had correlations significant at the $95 \%$ or greater level (i.e., correlations greater than $\sim 0.33$ ) and the highest correlations (greater than 0.7) were at stations in southern coastal areas along the Gulf of Alaska. These results indicate that the ERA downscaling reasonably reproduced the observed variability in seasonal rainfall amounts during the winter. This analysis was limited because deriving total station rainfall station observations from GHCN-D relies on accurate snowfall data, which can be challenging to measure (Rasmussen et al. 2012). Furthermore, accumulated snow
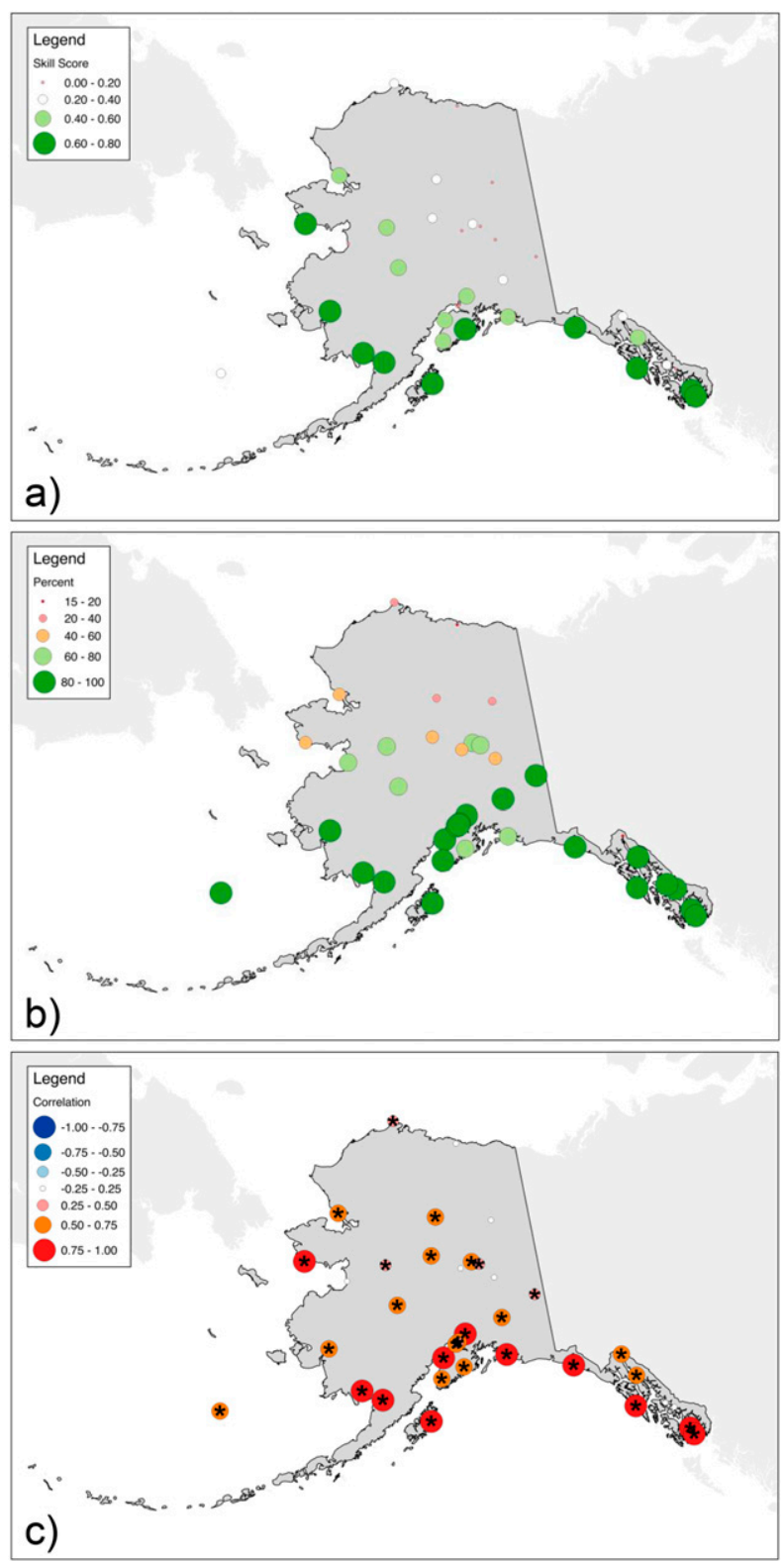

FIG. 4. METAR-derived November-March rain days vs nearest downscaled gridpoint rain days for 1979-2013: (a) Heidke skill score, (b) percent of station days captured by downscaling, and (c) correlation of seasonal counts of days. Correlations that are significant at a level of $95 \%$ or greater according to a $t$ test are marked by an asterisk in (c).

water equivalent was generally not available for most stations, which could have been used to more directly parse out rain versus snowfall on days with mixed precipitation.

The frequency of ROS days derived from downscaled ERA-Interim data showed varied agreement with the available, albeit limited, station and satellite observations. The general spatial climatic patterns of NovemberMarch downscaled ERA-Interim ROS days were similar 


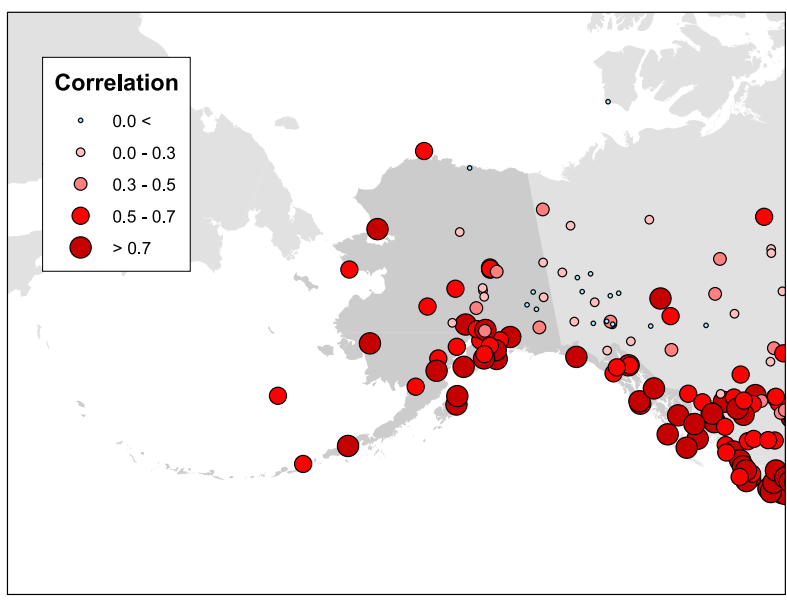

FIG. 5. Correlation between November-March 1979-2013 seasonal rainfall totals at Alaska weather stations and in the downscaled ERA-Interim dataset at the nearest grid point with the most similar elevation to the weather station.

to those found in previous studies for the Alaska region (Cohen et al. 2015; Jeong and Sushama 2018; Liston and Hiemstra 2011; McAfee et al. 2014; Putkonen and Roe 2003; Rennert et al. 2009; Wilson et al. 2013). The spatial variability of November-March 1979-2013 average rain days of the downscaled ERA-Interim was also comparable to that derived from the Alaska station network by two complementary methods. One key difference was that the stations had fewer events on average than the downscaled data. This issue appears to be tied to the overall wet bias that has been noted in the downscaled ERA-Interim (Bieniek et al. 2016). These extra days with precipitation/rainfall reduced the ability of the downscaled data to detect rain days when compared with the stations, especially in regions of the state where winter rain events are less common. Additional analysis also indicated that precipitation/rainfall occurs in interior Alaska during warm southerly flow over the Alaska mountain ranges when the station observed weather is warm but dry, that is during chinook events (not shown). This feature reduced the skill/correlations, especially around Fairbanks, which is directly north of the Alaska Range. The cause of this issue is currently speculative, but it could be due either to insufficient rain shadow effects from the $20-\mathrm{km}$ topography or to the initial/boundary forcing of the coarse ERA-Interim, which also has a wet bias relative to stations in Alaska (Lader et al. 2016).

A surprising result was that the coarse ERA-Interim had many more events than the downscaled version. Further analysis indicated that the ERA-Interim had many more days with light rainfall at temperatures well below $0^{\circ} \mathrm{C}$ than the downscaled ERA-Interim. Figure 6 shows an example for the grid point nearest Fairbanks

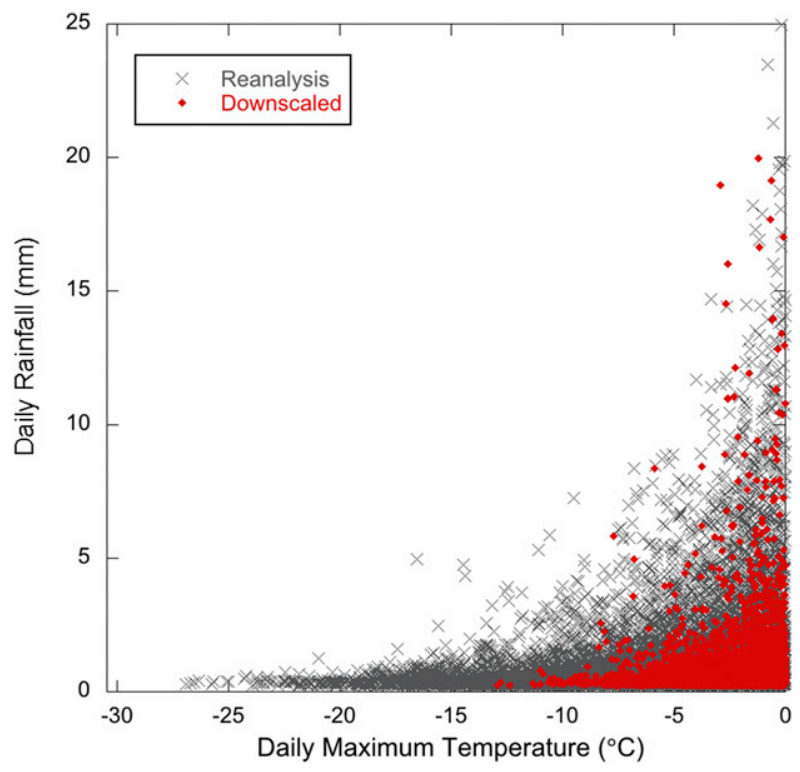

FIG. 6. The daily rainfall for ERA-Interim (gray) and downscaled ERA-Interim (red) vs corresponding daily maximum temperature at the Fairbanks grid point for November-March 1991-92.

over November 1991-March 1992 of daily rainfall versus daily maximum 2-m temperature. The reanalysis had many more days with rainfall at much lower temperatures than the downscaled ERA-Interim. Therefore, because the ROS criterion in our study was primarily based on rainfall, many more ROS events were detected in the reanalysis than in the downscaling. This issue likely occurred in the coarse reanalysis, in part, because the cloud microphysics scheme used for the ERA-Interim had a relatively simple representation of cloud and precipitation phase and allowed for mixed-phase clouds and precipitation down to $-23^{\circ} \mathrm{C}$ (Forbes and Ahlgrimm 2014). In contrast, the WRF Model configuration used the more complex Morrison two-moment scheme (Morrison et al. 2009), which was modified from the Morrison et al. (2005a) scheme that was built and tested to work with Arctic cloud microphysics (Morrison et al. 2005b). Furthermore, a test simulation with WRF was forced by the ERA-Interim for November 1991-March 1992, following the same model configuration, domain, and approach as the $20-\mathrm{km}$ downscaling procedure but with similar spatial resolution to the coarse ERAInterim (i.e., $75 \mathrm{~km}$ ). The results (not shown) revealed that the frequency and spatial distribution of ROS days for November 1991-March 1992 were nearly identical to the $20-\mathrm{km}$ downscaled output for the same period over Alaska. Therefore, the model physics was likely the key reason for the difference observed between ROS from the downscaled ERA-Interim and the more numerous events in the coarse ERA-Interim. 


\section{b. Drivers of extreme events}

The top 10 ROS days ranked by total rainfall were identified for Fairbanks, Anchorage, Utqiagvik, Bethel, Juneau, and Nome (Alaska) from the nearest downscaled ERA-Interim grid point over 1979-2013 (Table 1). One advantage of using the downscaled reanalysis data instead of station data to identify extremes is that it is simple to consistently separate liquid from solid precipitation to identify all ROS events; another is its consistency with the downscaled GCM projections that will be described in the next sections. Table 1 indicates that the southern coastal locations of Anchorage, Bethel, and Juneau had the highest rainfall amounts during the top 10 ROS events while Utqiagivik had the lowest amounts. The dates in Table 1 were compared with the station observations (not shown), and nearly all dates corresponded to high precipitation values in the observations. Of the six stations examined, only Utqiagivik and Fairbanks were problematic. Fairbanks is located north of the Alaska mountain range in a rain shadow that is often missed by the downscaling during chinook events with southerly winds resulting in the false identification of extreme ROS. The downscaled ERA-Interim also tended to produce extreme ROS days at Utqiagivik when there was low/no precipitation in the station observations. However, fully identifying the exact cause of these discrepancies would require investigation beyond the scope of this study. One challenge in evaluating the extremes is that ROS rainfall amounts cannot be directly derived to accurately account for days with mixed precipitation types at all stations like in the downscaled model output, making a direct ranking comparison problematic.

While challenges remain in accurately capturing ROS extremes in the dynamically downscaled reanalysis data for some locations, evaluating the typical spatial extents and atmospheric circulation drivers of the modeled ROS extremes in Alaska is a prudent next step. The percentages of grid points that had an ROS event on the same day as the top 10 events at each location are shown in Fig. 7 denoting the spatial extent typical of extreme ROS events that occur at each location. For Fairbanks (Fig. 7a), ROS was widespread during extreme days, extending toward the southwest and reaching the Bering Sea coast. Utqiagivik, Bethel, and Nome (Figs. 7c,d,f) also had similarly widespread ROS during extreme events. Anchorage and Juneau (Figs. 7b,e) had the most localized activity of all the locations during their extreme ROS events. These last two communities are located in the coastal mountains, so topographic effects that can locally enhance or more broadly block precipitation likely played a role in their ROS events being more concentrated than in the other areas. They are also 


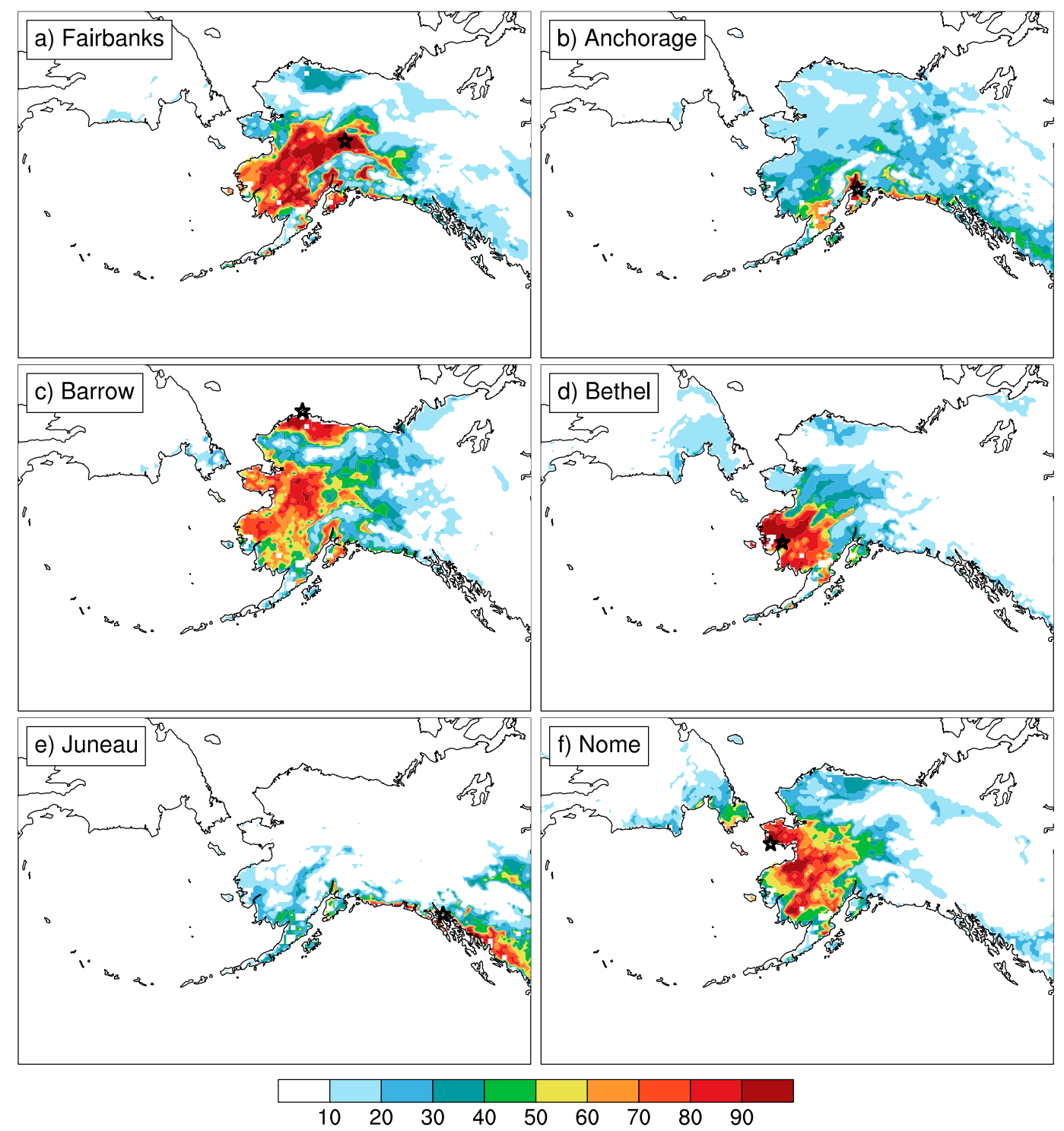

FIG. 7. Frequency of occurrence of ROS events during the top 10 events detected at (a) Fairbanks, (b) Anchorage, (c) Utqiagivik (Barrow), (d) Bethel, (e) Juneau, and (f) Nome for 1979-2013. The location of the station is shown by a star.

located in close proximity to the supply of relatively warm waters in the Gulf of Alaska and localized onshore winds can also bring ROS events.

Composite anomalies of SLP for the top 10 ROS days at each location are shown in Fig. 8. The top ROS days at all six locations commonly occurred with anomalous high pressure centered over the Gulf of Alaska to the south, or southeast. Anomalous low pressure was also typically centered to the west or north of the stations, but only Utqiagivik (Fig. 8c) and Nome (Fig. 8f) had a statistically significant low pressure anomaly signal. Assuming approximately geostrophic flow, the wind blows parallel to the lines of equal pressure. Therefore, all stations experienced anomalous south or southwesterly flow that would advect moisture from the relatively warm Pacific Ocean. Moisture advection is known to be a driver of heavy precipitation events in northern Alaska (Glisan and Gutowski 2014). The anomalous circulation patterns found in our composite analysis were broadly similar to those that led to extreme precipitation in winter at many of these same stations (Bieniek and Walsh 2017; L'Heureux et al. 2004) or regionally (Cassano and Cassano 2010). However, there were differences between the circulation patterns leading to heavy precipitation and extreme ROS days since ROS exclusively requires rainfall while heavy precipitation days 


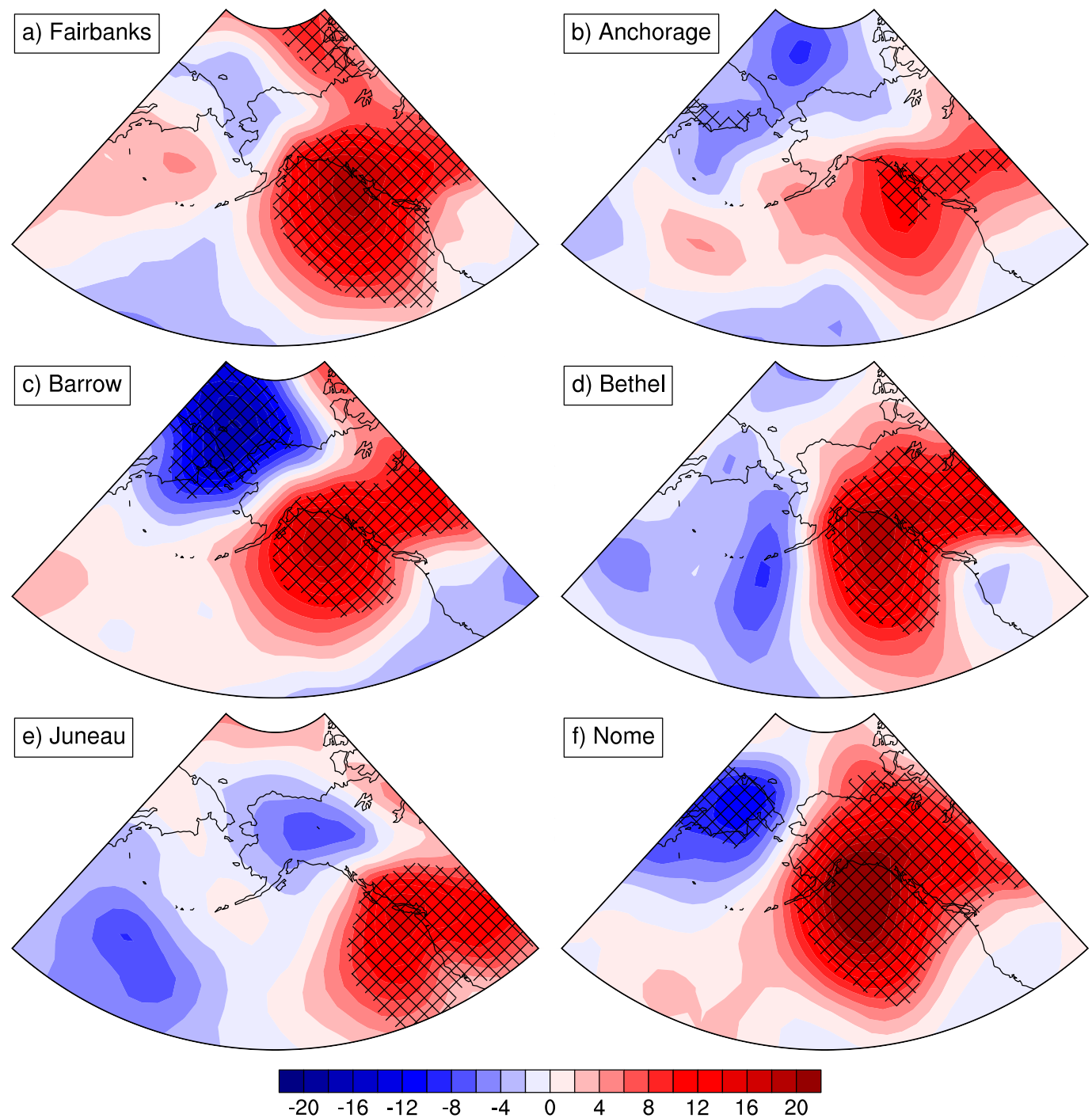

FIG. 8. Composite anomalies of daily sea level pressure (hPa) during the 10 events at (a) Fairbanks, (b) Anchorage, (c) Utqiagvik, (d) Bethel, (e) Juneau, and (f) Nome for 1979-2013. Anomalies that are significant at a level of $95 \%$ or greater are shown by crosshatching.

can encompass any combination of rain or snow. In most cases, only minor differences in the position or strength of the anomalous high pressure or storm track would be needed to sufficiently raise temperatures and lead to rain instead of snow. Rennert et al. (2009) specifically assessed 500 -hPa circulation patterns associated with ROS events for western Alaska and found a ridge centered over the Gulf of Alaska that was comparable to our findings.

On the basis of the findings of the SLP composite analysis, there is also a potential link between atmospheric rivers and heavy ROS events. Atmospheric rivers are relatively narrow channels of water vapor being transported through the troposphere in large quantities from lower latitudes. Wintertime atmospheric rivers moving into southern Alaska are associated with high pressure centered in the Gulf of Alaska (Mundhenk et al. 2016) and are characterized by a similar signal to the ROS SLP composites shown in Fig. 8. While considerable analysis beyond the scope of this study would be required to conclusively link extreme ROS events with atmospheric river activity, we speculate that the SLP patterns found in the composite analysis show that such events may have played a role. A better understanding of the intricate links between Alaska ROS events and atmospheric river events is especially important because it may provide a means of subseasonal-to-seasonal predictability (Baggett et al. 2017). 

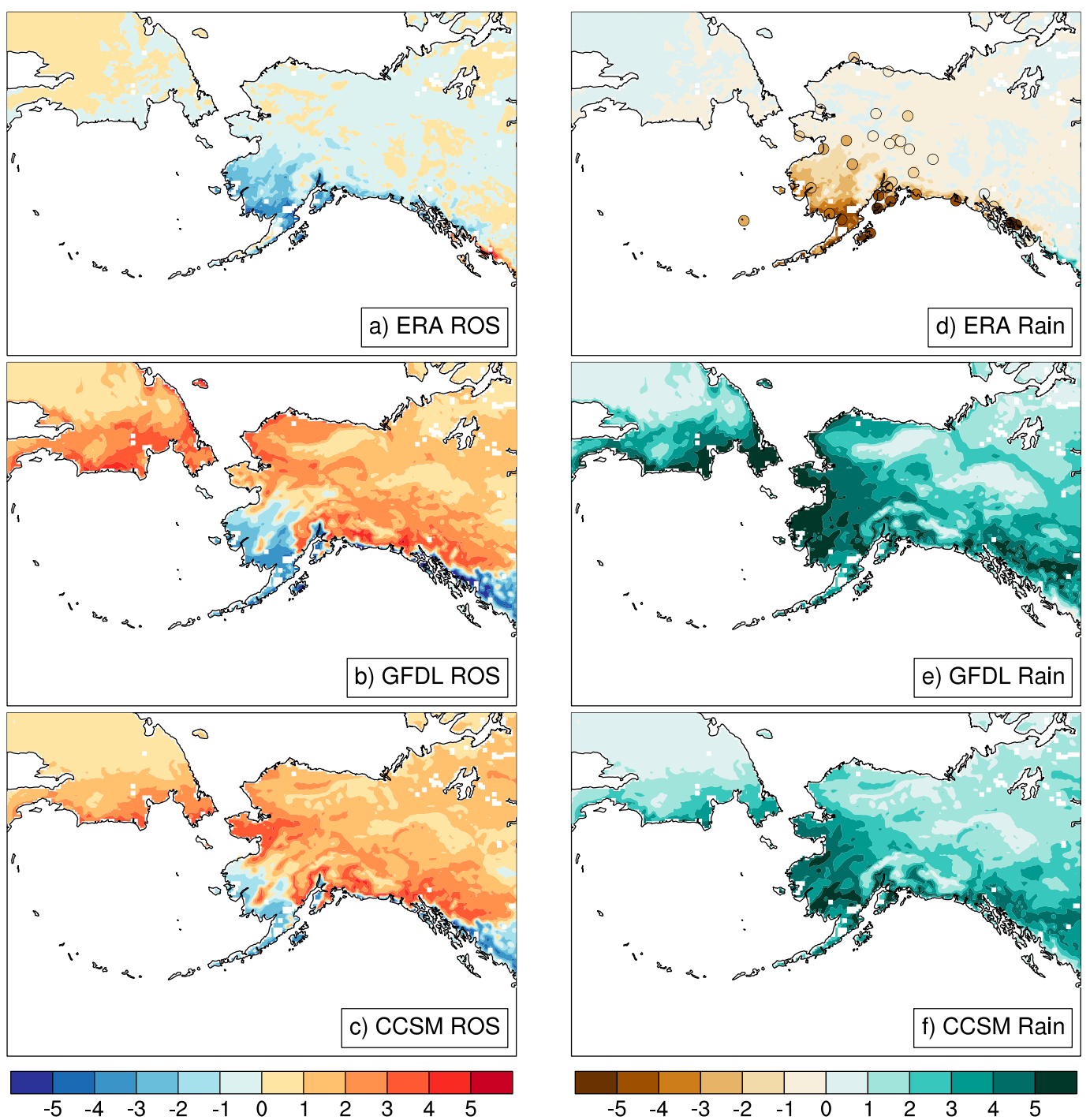

FIG. 9. Trends (days per $10 \mathrm{yr}$ ) in the number of November-March (a)-(c) ROS days and (d)-(f) rainfall days for (top) 1979-2013 for downscaled ERA-Interim and 2006-2100 for downscaled (middle) GFDL CM3 and (bottom) NCAR CCSM4 in Alaska. The trends in November-March number of station rainfall days for 1979-2013 are displayed in (d) as circles.

\section{c. Past and anticipated change}

The observed and future projected trends in the number of November-March ROS days are shown in Figs. 9a-c. Over the downscaled ERA-Interim period of 1979-2013, from one to four fewer ROS days per decade have occurred over southwestern Alaska (Fig. 9a). Other regions of the state had either no trends or weakly increasing trends of approximately $0-1$ ROS days per decade. The observed trend pattern is consistent with that observed by Cohen et al. (2015) for December-February using the Modern-Era Retrospective Analysis for Research and Applications (MERRA) reanalysis over 1980-2014. However, the declining ROS trends found in our analysis in southwestern Alaska were not as consistent with those of Liston and Hiemstra (2011), who reported mixed trends in the same region. Both Cohen et al. (2015) and Liston and Hiemstra (2011) used MERRA as the basis of their analysis. However, Liston and Hiemstra (2011) considered the full snow-cover season that extends beyond the November-March period, which may be responsible for this relatively minor discrepancy.

Downscaled projections over 2006-2100 according to the GFDL CM3 and NCAR CCSM4 GCMs indicated an increase in frequency of November-March ROS events by 1-3 days perdecade over much of Alaska (Figs. 9b,c). Similar to the observed trends, ROS events were projected to decline over southwestern Alaska 
by 1-4 days per decade. There was generally good spatial agreement between the two model projections with similar magnitudes of change. However, the extent of the decline in southwestern Alaska was slightly more pronounced in GFDL CM3 (Fig. 9b) than in NCAR CCSM4 (Fig. 9c). A similar spatial pattern of declining ROS in the southwest and increases elsewhere was also observed by Rennert et al. (2009) using the CCSM model. Jeong and Sushama (2018) downscaled selected CMIP5 models and scenarios over North America and identified a general increase in ROS days over Alaska by 2041-70 relative to 1976-2005 but did not have the decrease in ROS days over southwestern Alaska that was projected by our analysis. This difference could be because their ROS was identified only by rainfall on snow water equivalents of $1 \mathrm{~mm}$ or greater without the additional temperature criteria used in our analysis. Additionally, their trends were evaluated by taking the difference between two 30-yr periods and not over the entire record as in our analysis.

The trends during all historical and projected periods appeared to be linked to changes in rainfall. The frequency of days with rainfall or mixed rain and snow declined in southwestern Alaska over 1979-2013 based on the downscaled ERA-Interim (Fig. 9d) spatially corresponding to the declines observed in ROS events. Likewise, weak or no trends occurred over the rest of the domain. Local expert knowledge on these changes was limited but Alaskan native elders in southwestern Alaska have noted a tendency toward less rain in winter in recent decades and an effect of the reduced frequency of ROS events on the seasonal snowpack and their subsistence activities (Fienup-Riordan and Rearden 2012). Observed station trends in the number of rain days based on the METAR data are overlaid in Fig. 9d. The station trends generally match those of the downscaled ERA-Interim in both sign and magnitude. The results using the GHCN-D were similar and are therefore not shown.

Unlike the weak or declining rainfall trends in the observed reanalysis period, the future projections from GFDL CM3 and NCAR CCSM4 both indicated increases in rainfall days of 1-5 days per decade (Figs. 9e,f) over all of Alaska. The largest projected increases in rainfall days were in western Alaska and encompassed the area of projected ROS declines. Based on these findings, projected increases in ROS days were linked to more rainfall in winter for much of the state. However, southwestern Alaska was projected to experience declining ROS events, not because of decreasing rain, as in the 1979-2013 ERA-Interim period, but because of either higher surface temperatures or the absence of snow on the ground. Similar to our findings,
McAfee et al. (2014) observed that the snow-day fraction throughout Alaska would decline (i.e., days with rain will increase) by 2100 using four models of CMIP3. Bintanja and Andry (2017) noted more broadly that rainfall in the Arctic is generally expected to increase, while snowfall declines, by 2100 based on a study of 37 CMIP5 models. Therefore, the projections of rainier winters in Alaska according to the GFDL CM3 and NCAR CCSM4 scenarios were within the expected results of other future GCM projections from CMIP3 and CMIP5.

\section{d. High-impact extreme events}

The ice buildup left from ROS events can have major impacts on wildlife and transportation. In Alaska, these effects can be particularly severe because ice from ROS events can remain for months until temperatures rise above freezing during the spring melt. It is, therefore, especially important for key Alaska stakeholders to be able to better forecast ROS events from days to decades in advance. The development of the Alaska downscaled gridded ROS dataset allows for the evaluation of highimpact extreme events in geographic areas where it was not possible previously.

In early October of 2003, there was a dramatic icing event south of Teshekpuk Lake on the North Slope of Alaska (Brown 2005, 246-268). Freezing rain on top of thawing and melting snow in the form of an ROS event made it difficult for caribou to forage. Nearly one-third of the Teshekpuk caribou herd (TCH) moved approximately $400 \mathrm{~km}$ to the east and wintered in the Arctic National Wildlife Refuge on the calving grounds of the Porcupine caribou herd. A move of this direction and this magnitude was unprecedented, and the mortality of collared TCH caribou in the winter of 2003/04 was the highest ever recorded, at 25\% (Brown 2005, 246-268). However, by 2008 the population size of the TCH had rebounded and increased to 64000 (Harper 2011, 83314), approximately 19000 higher than it had been in 2002 before the icing event (Brown 2005, 246-268). Impacts on wildlife from ROS are not unprecedented; Hansen et al. (2011) found multiyear correlations between icing events and growth rates of the reindeer population on Svalbard, Norway, and Forbes et al. (2016) observed high mortality rates of reindeer as a result of extreme ROS events in Russia.

Direct observations of the TCH ROS event were limited but examination of the October 2003 ROS data derived from the downscaled ERA-Interim revealed a major event in the range of the TCH on 1 October 2003 (Fig. 10). Rainfall on 1 October exceeded $10 \mathrm{~mm}$ over a large portion of the TCH range on the western North Slope (Fig. 10a). For many locations in the region this 

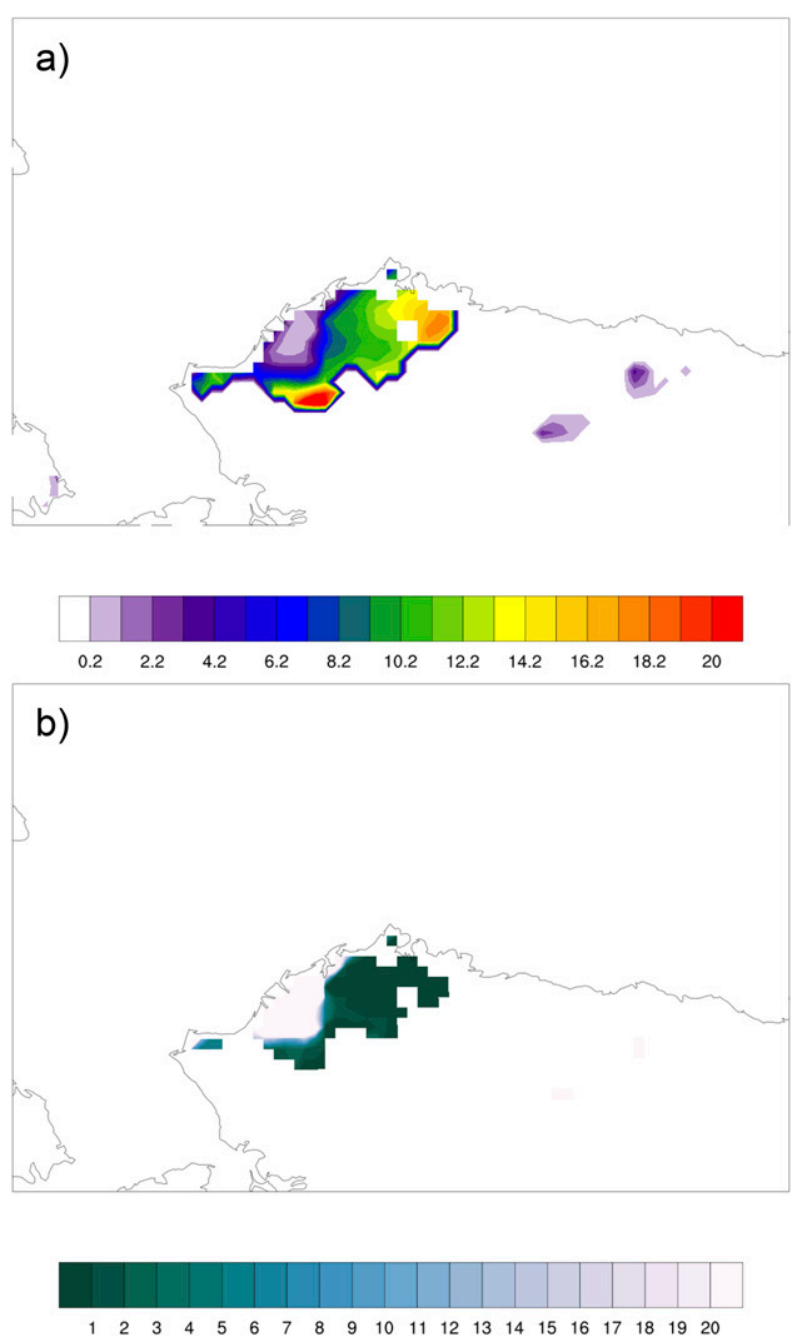

FIG. 10. (a) Amount of rainfall (mm) on 1 Oct 2003 and (b) rank of the 1 Oct 2003 ROS rainfall among all 1979-2013 NovemberMarch days at each grid point.

was the highest ROS-associated rainfall in the 19792013 records from the downscaled ERA-Interim (Fig. 10b). Limited station observations were available in the vicinity: Utqiagvik had only $5.8 \mathrm{~mm}$ of precipitation and Wainwright had $5 \mathrm{~mm}$ on 1 October 2003. Both of these stations are located along the coast where the downscaled reanalysis also indicated similarly smaller ROS rainfall amounts. Unfortunately, no in situ station observations were available in the inland core of the ROS event for direct validation.

Transportation is also strongly impacted by ROS events that leave ice on roadways. Limited detailed information was available for such events in Alaska, but the National Weather Service in Fairbanks had compiled a list of highimpact (i.e., rainfall greater than $2.5 \mathrm{~mm}$ ) ROS events since the late 1970s (Table 2). These events all caused dangerous
TABLE 2. Dates of significant observed ROS events for 19792013 in Fairbanks, as derived from National Weather Service records. Equivalent rankings from Table 1 are shown for comparison.

\begin{tabular}{lc}
\hline \hline Event date & ERA rank \\
\hline 14 Jan 2013 & 14 \\
22-24 Nov 2010 & 1,3 , and 7 \\
2-6 Nov 2003 & $100+$ \\
8-10 Feb 2003 & 10 \\
6-11 Nov 1979 & 5 \\
\hline
\end{tabular}

conditions on roadways and closed schools. This list was constructed through a manual combing of Fairbanks weather and climate observations. A first pass was made by extracting November-March days with anomalously low 24-h liquid-to-snow ratios. The most detailed weather information (usually scans of the original observation forms) for those days was then scrutinized to help to determine precipitation type. A $2.5-\mathrm{mm}$ rainfall threshold was chosen to reduce the ambiguity of winter rain events; however, smaller amounts of icing can also dramatically impact road conditions. Most of the ROS events listed in Table 2 occurred over multiple days and were linked with many of the top 10 ROS days that were identified by the downscaled ERA data and listed in Table 1.

Extreme ROS events such as the examples discussed above have the greatest societal and ecological impacts. The projections in the preceding section indicated that the number of ROS days were likely to increase around the state with a few exceptions and understanding how extremes are projected to change is of especially high importance. To project changes in extreme ROS days at each station location, the minimum daily rainfall amount required to be among the top 10 extreme events in the downscaled ERA-Interim was used as a threshold. The number of extreme November-March ROS days meeting the extreme threshold in the downscaled GCM projections were then totaled by $30-y r$ period. The percent change relative to the 1981-2010 period for 30-yr periods of the downscaled NCAR CCSM4 and GFDL CM3 model projections is shown in Fig. 11. This relativechange approach normalized the model outputs for comparison. Fairbanks, Utqiagvik, and Nome were all projected to have multifold increases in extreme ROS days by 2071-2100 based on the downscaled NCAR CCSM4 and GFDL CM3. Utqiagvik showed the largest projected increases, with 5-20 times as many events in 2071-2100 as in 1981-2010. In contrast, Anchorage, Bethel, and Juneau all had projected decreases in the frequency of days meeting present-day ROS extremes by $2071-2100$. Juneau was projected to have the largest decline in extreme ROS days by 2071-2100 to just 

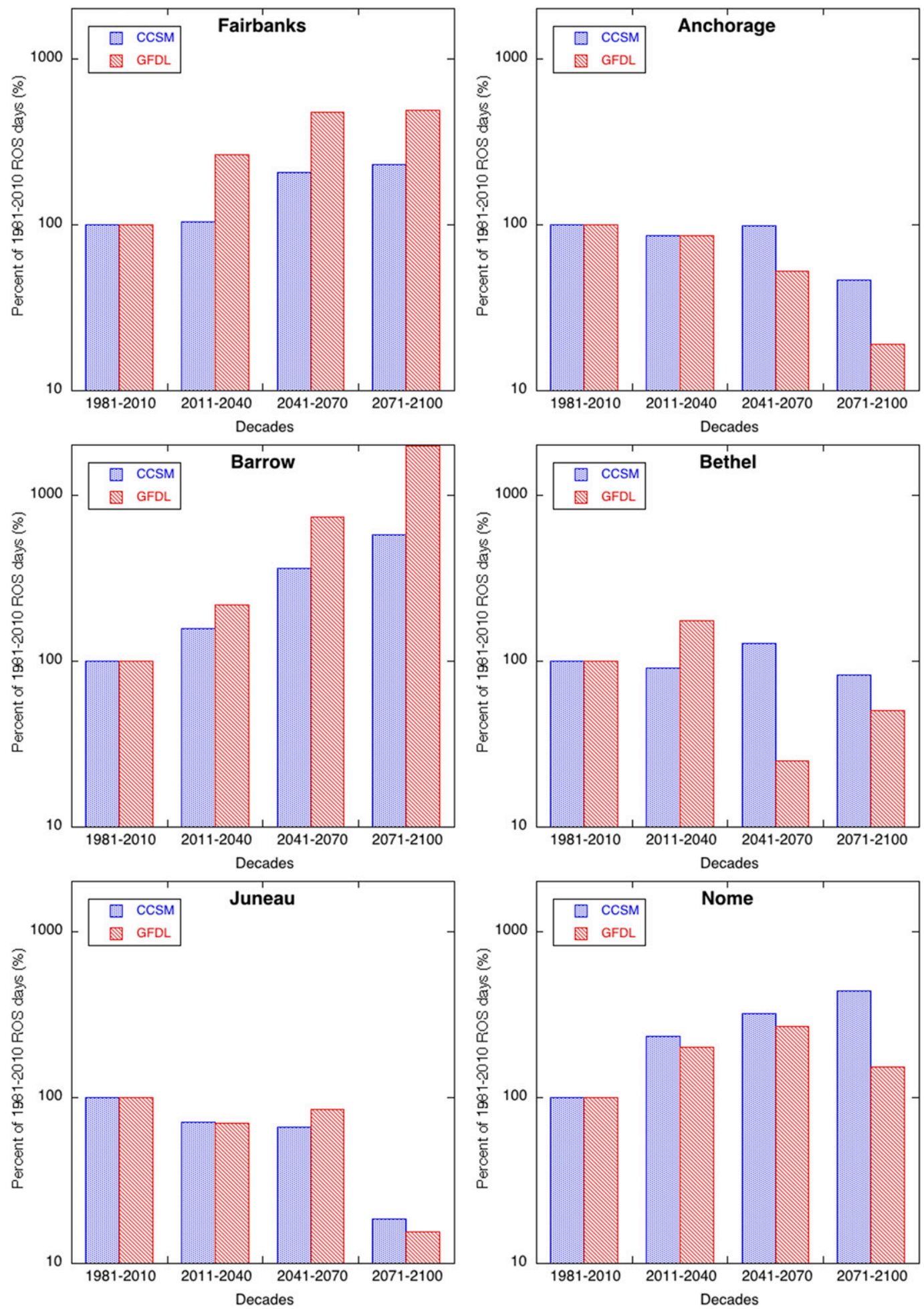

FIG. 11. Percent change per 30-yr period relative to 1981-2010 in the number of extreme ROS days at Fairbanks, Anchorage, Utqiagvik (Barrow), Bethel, Juneau, and Nome. Note the logarithmic scale of the $y$ axes. 
$15 \%-18 \%$ of the number of 1981-2010 occurrences. The direction of trends in extreme ROS days was the same as the direction of trends in all ROS days at all six locations.

\section{Conclusions}

Dynamical downscaling of the reanalysis data from ERA-Interim captured the overall seasonality of ROS events as well as their spatial extent and was comparable to available station/satellite observations but tended to be biased toward too many rain events. Some locations in interior and northern Alaska were especially problematic and also had issues with capturing ROS extremes. The downscaled ERA-Interim has previously been shown to have a wet bias, which is partially responsible for the extra ROS days, but some locations are also impacted by missed rain-shadow effects. However, the inclusion of WRF Model physics in the downscaling process substantially improved on the original ERAInterim dataset.

Extreme ROS events at key population centers throughout Alaska can have high impacts. These extreme days had atmospheric circulation signals that were similar to those of known winter extreme precipitation events. The circulation patterns all shared the common feature of anomalous high pressure centered in the Gulf of Alaska to the east and/or south of the station receiving ROS. The similarity with general heavy winter precipitation events poses a potential challenge to forecasters because it implies that a subtle change in the orientation of the atmospheric circulation patterns or temperature gradients can be the difference between a major ROS event and heavy snowfall.

The number of downscaled ROS days declined in southwestern Alaska over the 1979-2013 historical record because of a decline in the number of rain events, which was consistent with station observations. Projections to 2100 indicated increased likelihoods of ROS days in most parts of northern Alaska, with declines in southwestern and southern coastal regions. The downscaled GCMs projected increases in the frequency of rainfall in winter throughout all of Alaska; however, coastal regions ultimately warm sufficiently above $0^{\circ} \mathrm{C}$ to prevent the rainfall from meeting the ROS criterion. Extreme events at key population centers followed a similar pattern with increasing trends projected for Fairbanks, Utqiagivik, and Nome and decreasing trends projected for Anchorage, Bethel, and Juneau by 2100 .

The projected changes in the frequency of ROS days and in extremes have potential ecological implications. One of the largest caribou mortality events occurred during an extreme ROS event in northern Alaska. As the chances of such extremes increase through 2100, the risks for mortality events also similarly increase. The impact of these events will ultimately depend on the ability of a species to adapt to change. Similarly, increases in ROS events projected for the relatively roaddense Fairbanks region may impact winter transportation, and solutions will need to be explored to mitigate the impacts.

Refinement of regional and global climate models will be an important next step toward further improving our ability to diagnose and detect ROS events in Alaska. Further testing of model physics, resolution, topography, and initialization of WRF and other regional models is needed to better capture the sometimes tight spatial gradients of rain/precipitation in Alaska. Developing improved weekly to seasonal prediction systems for ROS events in Alaska is also a prudent next step since ROS events are projected to become more prevalent throughout Alaska in the future. The composite analysis showed typical atmospheric circulation patterns that accompany extreme ROS days, which could be used statistically in analog forecasting approaches. Future work should also identify the physical mechanisms related to extreme ROS events to further improve their predictability. To be successful, any forecasting approach would need to be able to separate ROS events from more general heavy snow events. Changes in upper-air conditions related to ROS events could also be of interest to the aviation community because icing conditions from the surface to the midtroposphere pose significant hazards to aircraft operations. The performance of model forecast systems should also be evaluated, with an eye toward improvements in the ability of model to capture these events diagnostically and prognostically.

Acknowledgments. The authors thank Jing Zhang and Jeremy Krieger for their assistance with WRF and Scott Rupp, Nathan Kettle, Richard Forbes, Kelvin Richards, and the two anonymous reviewers for their comments that helped to improve this study. The project described in this publication was supported by Cooperative Agreement G17AC00213 from the U.S. Geological Survey (USGS). The typescript was submitted for publication with the understanding that the U.S. government is authorized to reproduce and distribute reprints for governmental purposes. This work was supported in part by the high-performance computing and data storage resources operated by the Research Computing Systems Group at the University of Alaska Fairbanks, Geophysical Institute. 


\section{REFERENCES}

Baggett, C. F., E. A. Barnes, E. D. Maloney, and B. D. Mundhenk, 2017: Advancing atmospheric river forecasts into subseasonalto-seasonal time scales. Geophys. Res. Lett., 44, 7528-7536, https://doi.org/10.1002/2017GL074434.

Bieniek, P. A., and J. E. Walsh, 2017: Atmospheric circulation patterns associated with monthly and daily temperature and precipitation extremes in Alaska. Int. J. Climatol., 37, 208-217, https://doi.org/10.1002/joc.4994.

—, and Coauthors, 2012: Climate divisions for Alaska based on objective methods. J. Appl. Meteor. Climatol., 51, 1276-1289, https://doi.org/10.1175/JAMC-D-11-0168.1.

—, U. S. Bhatt, J. E. Walsh, T. S. Rupp, J. Zhang, J. R. Krieger, and R. Lader, 2016: Dynamical downscaling of ERA-Interim temperature and precipitation for Alaska. J. Appl. Meteor. Climatol., 55, 635-654, https://doi.org/10.1175/JAMC-D-15-0153.1.

Bintanja, R., and O. Andry, 2017: Towards a rain-dominated Arctic. Nat. Climate Change, 7, 263-267, https://doi.org/10.1038/ nclimate 3240.

Brooks, C. E., 1953: Handbook of Statistical Methods in Meteorology. Her Majesty's Stationery Office, $412 \mathrm{pp}$.

Brown, C., Ed., 2005: Caribou management report of survey and inventory activities: 1 July 2002-30 June 2004. Alaska Dept. of Fish and Game Wildlife Management Rep., 292 pp.

Cassano, E. N., and J. J. Cassano, 2010: Synoptic forcing of precipitation in the Mackenzie and Yukon River basins. Int. J. Climatol., 30, 658-674, https://doi.org/10.1002/joc.1926.

Cohen, J., H. Ye, and J. Jones, 2015: Trends and variability in rainon-snow events. Geophys. Res. Lett., 42, 7115-7122, https:// doi.org/10.1002/2015GL065320.

Dee, D. P., and Coauthors, 2011: The ERA-Interim reanalysis: Configuration and performance of the data assimilation system. Quart. J. Roy. Meteor. Soc., 137, 553-597, https://doi.org/ 10.1002/qj.828.

Fienup-Riordan, A., and A. Rearden, 2012: Ellavut: Our Yup'ik World \& Weather: Continuity and Change on the Bering Sea Coast. University of Washington Press, $354 \mathrm{pp}$.

Forbes, B. C., and Coauthors, 2016: Sea ice, rain-on-snow and tundra reindeer nomadism in Arctic Russia. Biol. Lett., 12, 20160466, https://doi.org/10.1098/rsbl.2016.0466.

Forbes, R. M., and M. Ahlgrimm, 2014: On the representation of high-latitude boundary layer mixed-phase cloud in the ECMWF Global Model. Mon. Wea. Rev., 142, 3425-3445, https://doi.org/10.1175/MWR-D-13-00325.1.

Glisan, J. M., and W. J. Gutowski Jr., 2014: WRF winter extreme daily precipitation over the North American CORDEX Arctic. J. Geophys. Res. Atmos., 119, 10738-10748, https://doi.org/ 10.1002/2014JD021676.

Hansen, B. B., R. Aanes, I. Herfindal, J. Kohler, and B.-E. Sæther, 2011: Climate, icing, and wild arctic reindeer: Past relationships and future prospects. Ecology, 92, 1917-1923, https://doi.org/ 10.1890/11-0095.1.

Harper, P., Ed., 2011: Caribou management report of survey and inventory activities: 1 July 2008-30 June 2010. Alaska Department of Fish and Game Wildlife Management Rep. (Project 3.0), 345 pp., https://irma.nps.gov/DataStore/ DownloadFile/552796.

Iacono, M. J., J. S. Delamere, E. J. Mlawer, M. W. Shephard, S. A. Clough, and W. D. Collins, 2008: Radiative forcing by longlived greenhouse gases: Calculations with the AER radiative transfer models. J. Geophys. Res., 113, D13103, https://doi.org/ 10.1029/2008JD009944.
IPCC, 2013: Climate Change 2013: The Physical Science Basis. Cambridge University Press, 1535 pp., https://doi.org/10.1017/ CBO9781107415324 .

Janjić, Z., 1994: The step-mountain eta coordinate model: Further developments of the convection, viscous sublayer, and turbulence closure schemes. Mon. Wea. Rev., 122, 927-945, https://doi.org/ 10.1175/1520-0493(1994)122<0927:TSMECM > 2.0.CO;2.

Jeong, D. I., and L. Sushama, 2018: Rain-on-snow events over North America based on two Canadian regional climate models. Climate Dyn., 50, 303-316, https://doi.org/10.1007/s00382-017-3609-x.

Kalnay, E., and Coauthors, 1996: The NCEP/NCAR 40-Year Reanalysis Project. Bull. Amer. Meteor. Soc., 77, 437-471, https:// doi.org/10.1175/1520-0477(1996)077<0437:TNYRP>2.0.CO;2.

Kruse, J., D. Klein, S. Sraund, L. Moorehead, and B. Simeone, 1998: Co-management of natural resources: A comparison of two caribou management systems. Hum. Organ., 57, 447-458, https://doi.org/10.17730/humo.57.4.q5825utw35841p11.

Lader, R., U. S. Bhatt, J. E. Walsh, T. S. Rupp, and P. A. Bieniek, 2016: Two-meter temperature and precipitation from atmospheric reanalysis evaluated for Alaska. J. Appl. Meteor. Climatol., 55, 901-922, https://doi.org/10.1175/ JAMC-D-15-0162.1.

L'Heureux, M. L., M. E. Mann, B. I. Cook, B. E. Gleason, and R. S. Vose, 2004: Atmospheric circulation influences on seasonal precipitation patterns in Alaska during the latter 20th century. J. Geophys. Res., 109, D06106, https://doi.org/10.1029/ 2003JD003845.

Lindsay, R., M. Wensnahan, A. Schweiger, and J. Zhang, 2014: Evaluation of seven different atmospheric reanalysis products in the Arctic. J. Climate, 27, 2588-2606, https://doi.org/ 10.1175/JCLI-D-13-00014.1.

Liston, G. E., and C. A. Hiemstra, 2011: The changing cryosphere: Pan-Arctic snow trends (1979-2009). J. Climate, 24, 56915712, https://doi.org/10.1175/JCLI-D-11-00081.1.

McAfee, S. A., J. Walsh, and T. S. Rupp, 2014: Statistically downscaled projections of snow/rain partitioning for Alaska. Hydrol. Processes, 28, 3930-3946, https://doi.org/10.1002/hyp.9934.

Menne, M. J., I. Durre, R. S. Vose, B. E. Gleason, and T. G. Houston, 2012: An overview of the Global Historical Climatology Network-Daily database. J. Atmos. Oceanic Technol., 29, 897-910, https://doi.org/10.1175/JTECH-D-11-00103.1.

Morrison, H., J. Curry, and V. Khvorostyanov, 2005a: A new double-moment microphysics parameterization for application in cloud and climate models. Part I: Description. J. Atmos. Sci., 62, 1665-1677, https://doi.org/10.1175/JAS3446.1.

,-- M. Shupe, and P. Zuidema, 2005b: A new doublemoment microphysics parameterization for application in cloud and climate models. Part II: Single-column modeling of Arctic clouds. J. Atmos. Sci., 62, 1678-1693, https://doi.org/ 10.1175/JAS3447.1.

— G. Thompson, and V. Tatarskii, 2009: Impact of cloud microphysics on the development of trailing stratiform precipitation in a simulated squall line: Comparison of one- and two-moment schemes. Mon. Wea. Rev., 137, 991-1007, https:// doi.org/10.1175/2008MWR2556.1.

Mundhenk, B. D., E. A. Barnes, E. D. Maloney, and K. M. Nardi, 2016: Modulation of atmospheric rivers near Alaska and the U.S. west coast by northeast Pacific height anomalies. J. Geophys. Res. Atmos., 121, 12 751-12 765, https://doi.org/ 10.1002/2016JD025350.

Peters, G. P., and Coauthors, 2013: The challenge to keep global warming below $2^{\circ} \mathrm{C}$. Nat. Climate Change, 3, 4-6, https://doi.org/ 10.1038/nclimate1783. 
Putkonen, J., and G. Roe, 2003: Rain-on-snow events impact soil temperatures and affect ungulate survival. Geophys. Res. Lett., 30, 1188, https://doi.org/10.1029/2002GL016326.

Rasmussen, R., and Coauthors, 2012: How well are we measuring snow? The NOAA/FAA/NCAR winter precipitation test bed. Bull. Amer. Meteor. Soc., 93, 811-829, https://doi.org/10.1175/ BAMS-D-11-00052.1.

Rennert, K. J., G. Roe, J. Putkonen, and C. M. Bitz, 2009: Soil thermal and ecological impacts of rain on snow events in the circumpolar Arctic. J. Climate, 22, 2302-2315, https://doi.org/ 10.1175/2008JCLI2117.1.

Serreze, M. C., and R. G. Barry, 2011: Processes and impacts of Arctic amplification: A research synthesis. Global Planet. Change, 77, 85-96, https://doi.org/10.1016/j.gloplacha.2011.03.004.

Shulski, M., and G. Wendler, 2007: The Climate of Alaska. University of Alaska Press, 216 pp.
Skamarock, W. C., and Coauthors, 2008: A description of the Advanced Research WRF version 3. NCAR Tech. Note NCAR/ TN-475+STR, 113 pp., http://dx.doi.org/10.5065/D68S4MVH.

Walsh, J. E., and Coauthors, 2018: Downscaling of climate model output for Alaska. Environ. Modell. Software, https://doi.org/ 10.1016/j.envsoft.2018.03.021, in press.

Wilson, R. R., A. Bartsch, K. Joly, J. H. Reynolds, A. Orlando, and W. M. Loya, 2013: Frequency, timing, extent, and size of winter thaw-refreeze events in Alaska 2001-2008 detected by remotely sensed microwave backscatter data. Polar Biol., 36, 419-426, https://doi.org/10.1007/s00300012-1272-6.

Zhang, X., and J. Zhang, 2001: Heat and freshwater budgets and pathways in the Arctic Mediterranean in a coupled ocean/seaice model. J. Oceanogr., 57, 207-237, https://doi.org/10.1023/ A:1011147309004. 